\begin{tabular}{lcccr} 
T H E & A R C H I V E & O F & M E C H A N I C A L & E N G I N E E R I N G \\
\hline VOL. LIX & 2012 & Number 4
\end{tabular}

10.2478/v10180-012-0024-z

Key words: thrust bearing, elastohydrodynamic contact, Reynolds equation

MIKHAIL TEMIS *, ALEXANDER LAZAREV*

\title{
ELASTOHYDRODYNAMIC CONTACT MODEL FOR CALCULATION OF AXIAL AND ANGULAR STIFFNESS IN THRUST BEARING
}

\begin{abstract}
Thrust bearing model is developed for fluid flow calculation and for determination of bearing integral characteristics in the presence of sliding surfaces closure and shaft angular displacements. The model is based on the coupled solution of the problem of incompressible fluid flow between the sliding surfaces and the problem of bearing and shaft elements deformation under the action of the fluid film pressure. Verification of the bearing model results is carried out by the comparison versus the fluid flow calculation results obtained by STAR-CD software and the experimental and theoretical results represented in the certain literature. Thrust bearing characteristics are determined versus sliding surfaces closure and rotating disk (runner) angular displacements. The contribution of the sliding surfaces deformations into bearing integral characteristics is estimated.
\end{abstract}

\section{Introduction}

Hydrodynamic thrust bearing is used for compensation of the unbalanced axial force acting on rotor. Thrust bearings with hydrodynamic lubrication are used in high- and low-speed rotor supports of the stationary gas turbine units and testing rigs. Hydrodynamic lubricant in bearing has a considerably nonlinear stiffness and damping characteristics and hence influences stationary gas turbine unit rotor stiffness and damping characteristics.

Rotor rotating produces angular displacements as a rigid body, as well as bending displacements, which also cause the runner's angular displacements. So, despite the fact that the thrust bearing function is compensation of the rotor axial deflection, the runner's angular displacement leads to the production of a moment preventing this displacement that has an influence on the rotor's bending stiffness characteristics when it oscillates. The thrust

* Mathematical Simulation Department, Central Institute of Aviation Motors, Moscow, Russia; E-mail: tejoum@ciam.ru 
bearing, due to its nonlinear stiffness and damping properties, may considerably affect rotor nonlinear vibrations pattern. The influence pattern that the thrust bearing has on rotor dynamics is insufficiently investigated at present times. It may be investigated after the development of an adequate thrust bearing model. Therefore, one of the main problems that exists in the static and dynamic analysis of a slide-bearings supported rotor is the calculation of thrust bearing stiffness and damping characteristics in the presence of the axial closure between the bearing sliding surfaces and with runner angular displacements taken into account. Experimental and numerical investigations of the lubricant flow in a thrust bearing with rigid sliding surfaces and the runner parallel to the thrust plate are presented in [1].

Despite all that - the gap between runner and thrust plate for a high axial loading is sufficiently small for providing sufficient fluid film pressure values in bearing. In such a case, deformations of sliding surfaces, produced by the fluid film pressure, are comparable with the fluid film thickness values. Particularly, this may have considerable effect on bearings with antifriction coating with low modulus of elasticity values that are widely used in rotor supports. As shown in papers [2-4], for radial bearings, changes in fluid film thickness for radial bearings due to radial deformations of the bearing working surfaces considerably influence the carrying force value and direction, and hence the rotor dynamic characteristics. Similar phenomenon must be considered for the thrust bearing (Fig. 1). The following symbols are used in Fig. $1: R_{1}$ - internal radius; $R_{2}$ - external radius; $\theta$ - lobe angle; $h_{\min }$ and $h_{\max }$ - minimal and maximal gap thicknesses, respectively; $\gamma-$ shaft axis rotation angle; $\omega$ - shaft revolution speed; $\xi$ - angle of the shaft axis rotation plane; $\varphi$ - angular coordinate; $r$ - radial coordinate.

In the paper, the methodology for bearing stiffness calculation is developed on the example of a 6-lobe thrust bearing with working surfaces deformability and runner angular displacements taken into account. The presented methodology was verified versus experimental and numerical data published by Mote et al. [1] and calculations results obtained via STAR-CD software.

\section{Model of incompressible fluid flow in the thrust bearing}

Generally, the fluid flow in the bearing is described by the Navier-Stokes equations for viscous incompressible fluid that has the following form in cylindrical coordinates $(r, \varphi, z)$ : 


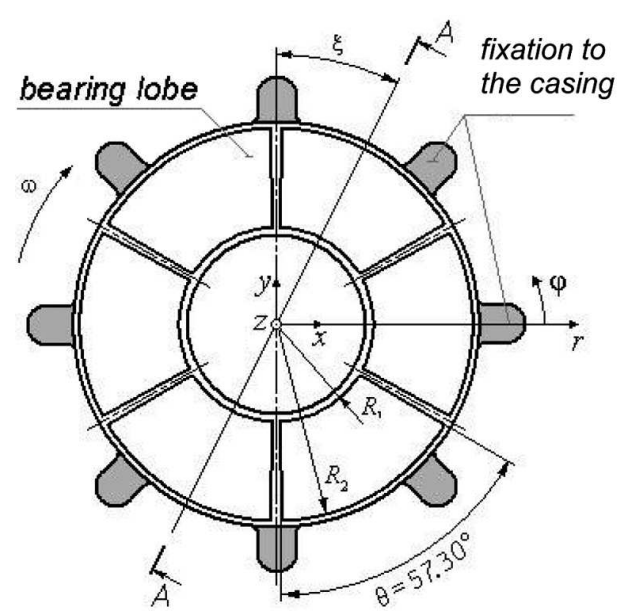

a)

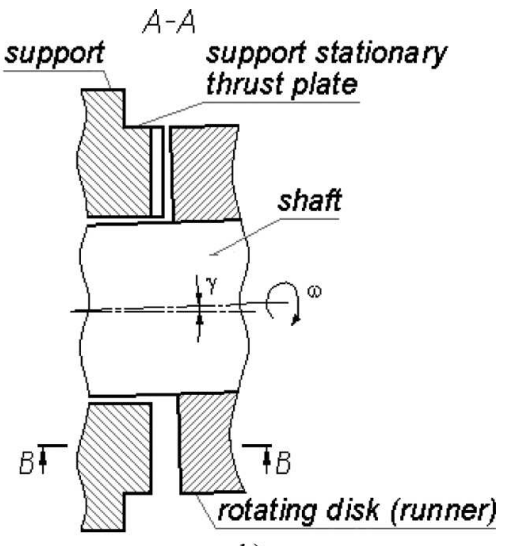

b)

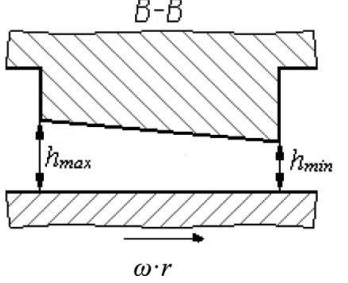

Fig. 1. 6- lobe thrust bearing structure: a - lobes locations; b, $c$ - bearing cross-sections

$$
\left\{\begin{array}{c}
\frac{\partial v_{r}}{\partial t}+(V \nabla) v_{r}-\frac{v_{\phi}^{2}}{r}=f_{r}-\frac{1}{\rho} \frac{\partial p}{\partial r}+\frac{\eta}{\rho}\left(\Delta v_{r}-\frac{v_{r}}{r^{2}}-\frac{2}{r^{2}} \frac{\partial v_{\phi}}{\partial \phi}\right) \\
\frac{\partial v_{\phi}}{\partial t}+(V \nabla) v_{\phi}+\frac{v_{r} v_{\phi}}{r}=f_{\phi}-\frac{1}{\rho r} \frac{\partial p}{\partial \phi}+\frac{\eta}{\rho}\left(\Delta v_{\phi}-\frac{v_{\phi}}{r^{2}}+\frac{2}{r^{2}} \frac{\partial v_{r}}{\partial \phi}\right) \\
\frac{\partial v_{z}}{\partial t}+(V \nabla) v_{z}=f_{z}-\frac{1}{\rho} \frac{\partial p}{\partial z}+\frac{\eta}{\rho} \Delta v_{z}
\end{array}\right.
$$

where $\left(v_{r}, v_{\varphi}, v_{z}\right)$ is the fluid flow velocity vector, $\left(f_{r}, f_{\varphi}, f_{z}\right)$ is a mass forces vector, $\rho$ is a fluid density, $t$ is a time, $p$ is a fluid pressure, $\eta$ is the fluid dynamic viscosity, operators $(V \nabla)$ and $\Delta$ defined as:

$$
(V \nabla) f=v_{r} \frac{\partial f}{\partial r}+\frac{v_{\phi}}{r} \frac{\partial f}{\partial \phi}+v_{z} \frac{\partial f}{\partial z}, \Delta f=\frac{1}{r} \frac{\partial}{\partial r}\left(r \frac{\partial f}{\partial r}\right)+\frac{1}{r^{2}} \frac{\partial^{2} f}{\partial \phi^{2}}+\frac{\partial^{2} f}{\partial z^{2}} .
$$

Laminar flow of the incompressible liquid without slippage, which is defined by the shaft revolution speeds and relative bearing clearance dimensions, is considered in the mathematical model of the fluid flow in the bearing. Taking into account that the order of magnitude of terms in equations (1) is unequal for flow in thin layer, one can draw the following conclusions [5]: mass and inertia forces of the liquid particles are negligible 
in comparison with the viscosity forces for the concerned bearing structure and operating conditions; velocity component perpendicular to the sliding surfaces is negligible in comparison with the components directed along the sliding surfaces $\left(v_{z}<<v_{r}, v_{\phi}\right)$; the derivatives of $r$ and $\varphi$ coordinates of any velocity component are smaller by the factor of $h^{*} / l$ in comparison with $z$ coordinate derivative of the same velocity component $\left(h^{*}\right.$ and $l$ are characteristic dimensions of gap and sliding surface length for the thrust bearing). The simplification of Navier-Stokes equations (1) and the table showing relative order of derivatives magnitudes are presented in detail in [6]. Taking into account the above-listed assumptions, we may represented the Navier-Stokes equations describing the fluid flow in thrust bearing in the following form:

$$
\left\{\begin{array}{c}
\frac{\partial p}{\partial r}=\eta \frac{\partial^{2} v_{r}}{\partial z^{2}} \\
\frac{1}{r} \frac{\partial p}{\partial \phi}=\eta \frac{\partial^{2} v_{\phi}}{\partial z^{2}} \\
\frac{\partial p}{\partial z}=0
\end{array}\right.
$$

Expressions for the velocity vector components $v_{r}$ and $v_{\varphi}$ are obtained by integration of equation (2) and substituting it into the fluid continuity equation:

$$
\int_{0}^{h(r, \phi)} \frac{1}{r} \frac{\partial\left(r v_{r}\right)}{\partial r} d z+\int_{0}^{h(r, \phi)} \frac{1}{r} \frac{\partial v_{\phi}}{\partial \phi} d z+\int_{0}^{h(r, \phi)} \frac{\partial v_{z}}{\partial z} d z=0,
$$

and after taking into account the boundary conditions for the thrust bearing are reformated into the two-dimensional Reynolds equation describing the fluid flow in the small sized channel:

$$
\frac{\partial}{\partial r}\left(r h^{3}(r, \phi) \frac{\partial p(r, \phi)}{\partial r}\right)+\frac{1}{r} \frac{\partial}{\partial \phi}\left(h^{3}(r, \phi) \frac{\partial p(r, \phi)}{\partial \phi}\right)=6 \eta \omega r \frac{\partial h(r, \phi)}{\partial \phi},
$$

where the coordinate axes $r$ and $\varphi$ are chosen as it is shown in Fig. 1a; $p=p(r, \varphi)-$ pressure function over the lobe surface; $h=h(r, \varphi)$ - fluid film thickness determined, in general case, by the initial form and the changes in sliding surfaces mutual position (runner displacement and rotations $)-h_{\text {geom }}(r, \varphi)$ and also the sliding surfaces deformations under the action of hydrodynamic pressure $h_{d e f}(r, \varphi)$ [2-4]:

$$
h(r, \phi)=h_{\text {geom }}(r, \phi)+h_{\text {def }}(r, \phi) .
$$

The sliding surfaces deformations $h_{\text {def }}(r, \varphi)$, caused by the action of fluid pressure $p(r, \varphi)$ in the gap are considered in the calculation of $h(r, \varphi)$ 
according to the solution of stress-strain state of bearing components. The sliding surfaces displacements in the bearing, treated as absolutely rigid with respect to each other, $h_{\text {geom }}(r, \varphi)$, are considered in calculation of $h(r, \varphi)$ in the following form:

$$
h_{\text {geom }}(r, \phi)=h_{\min }+r \cdot\left[\sin \left(\phi-\frac{2 \pi(n-1)}{N}\right) \frac{h_{\max }-h_{\min }}{R_{2} \sin \theta}+\sin (\phi-\xi) \cdot \operatorname{tg}(\gamma)\right] \text {, }
$$

where $n$ - lobe number, $N$ - total number of lobes, $h_{\min }$ is a minimal gap value when the shaft axis is still.

Equation (4) is solved numerically with the usage of finite elements method and after the finite-element discretization procedure [7] being implemented it is reduced to the following system of nonlinear finite-element equations for pressure calculation:

$$
\left[K_{f}\left(h_{d e f}\right)\right]\{p\}=\left\{Q_{f}\left(h_{d e f}\right)\right\}
$$

where $\left[K_{f}\left(h_{d e f}\right)\right]$ is the system matrix for pressure calculation, with the coefficients depending on pressure distribution, valid for the case of the bearing with compliant sliding surfaces; $\left\{Q_{f}\left(h_{\text {def }}\right)\right\}$ is the right side vector, with the components also dependent on pressure distribution for the bearing with compliant sliding surfaces. Pressures on the contours of the calculation area are assumed to be equal to ambient pressure and stated as the boundary conditions.

\section{Bearing fluid flow model verification}

\subsection{Comparison with the results obtained via STAR-CD software}

Three-dimensional fluid film in the thrust bearing model was designed via STAR-CD software for verification of the model on the base of Reynolds equation. Calculations via STAR-CD were carried out on the basis of full Navier-Stokes equations. In the three-dimensional model, as well as in twodimensional one, described above, a laminar incompressible fluid flow is assumed without slippage and with a constant temperature distribution over the calculation area. At the same time, in contrast to the model based on the Reynolds equation, the three-dimensional model takes into account the action of mass forces and also the influence of the fluid speeds along rotor revolution axis and fluid accelerations in the bearing plane. Finite volumes method was used in STAR-CD calculations. Calculation area for the fluid film was divided into approximately 2 million 8-node quadrilaterals. Meshing and 


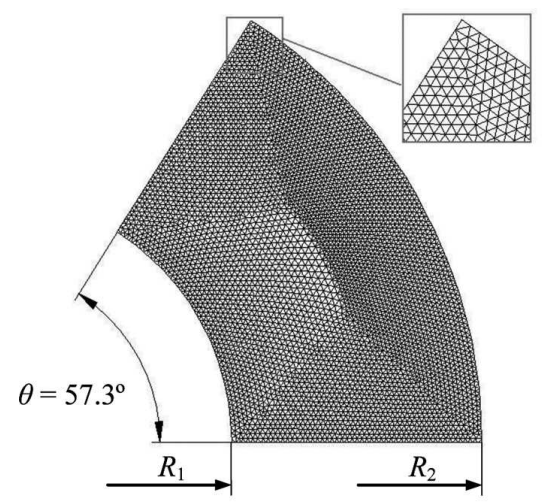

a)

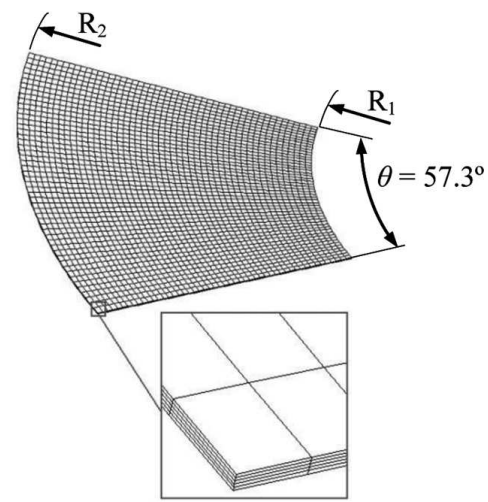

b)

Fig. 2. Meshing: a - two-dimensional finite-element mesh of the lobe surface for Reynolds equation; $b$ - three-dimensional meshing of the fluid film for STAR-CD

elements of the calculation area in STAR-CD and for Reynolds equation are shown in Fig. 2.

The comparison between the pressure distribution calculation results for two-dimensional Reynolds equation model and those obtained for the threedimensional STAR-CD model is carried out for the 6-lobe bearing with the internal radius $R_{1}=50 \mathrm{~mm}$, external radius $R_{2}=100 \mathrm{~mm}$, lobe angle $\theta=57.30^{\circ}$, water as a fluid and shaft rotating frequency of $2000 \mathrm{rpm}$. The difference between maximal $\left(h_{\max }\right)$ and minimal $\left(h_{\min }\right)$ gap is assumed constant and equal to $80 \mu \mathrm{m}$ and the shaft axis is still $(\gamma=0)$. The bearing carrying force versus minimal gap $h_{\min }$ is determined as the result of the calculations.

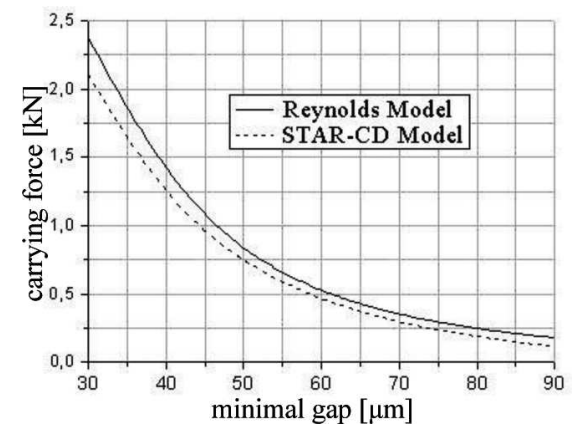

Fig. 3. Comparison of thrust bearing carrying force for two models

As it can be seen from the graphs shown in Fig. 3, the calculation results obtained by means of the two-dimensional Reynolds equation model are quite similar to the results obtained with the use the three-dimensional STAR-CD model. Pressure distributions over the lobe surface for $h_{\min }=50 \mu \mathrm{m}$, 
presented in Fig. 4, also show high degree of coincidence between the results yielded by both models.

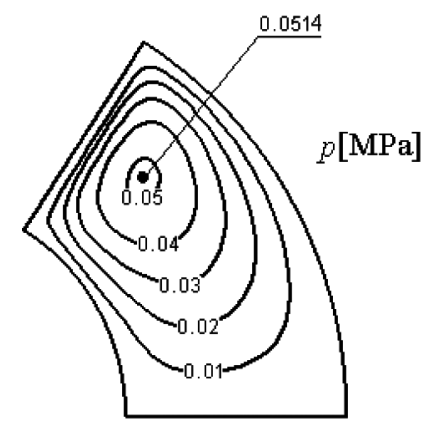

a)

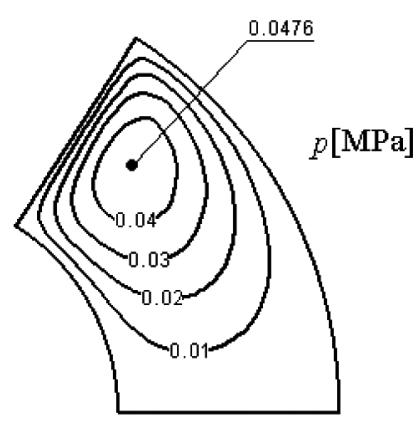

b)

Fig. 4. Pressure over the lobe surface for $h_{\min }=50 \mu \mathrm{m}$ : a - Reynolds model; $\mathrm{b}-\mathrm{STAR}-\mathrm{CD}$ model

\subsection{Comparison with the Mote results}

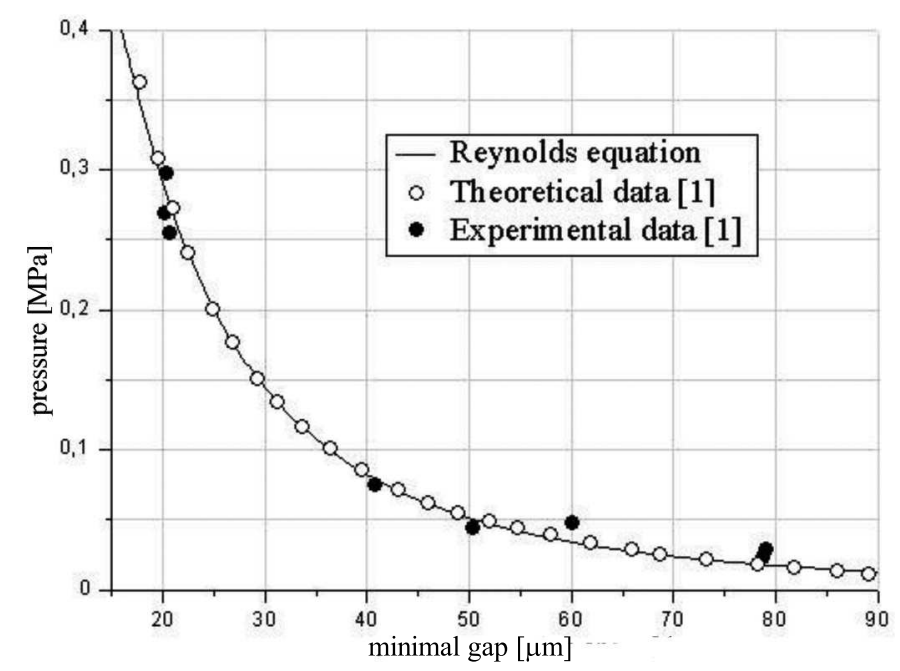

Fig. 5. Comparison of pressure at the lobe point with results from [1]

Theoretical and experimental results from [1] for the pressure in 6-lobe thrust bearing with the parameters mentioned above are used for verification of the developed model. The result of comparison at the point with polar coordinates $r=75 \mathrm{~mm}, \varphi=43^{\circ}$ shows a high degree of coincidence between the developed mathematical model and theoretical and experimental data from [1], which confirms the correctness of the developed model. Pressure at that point versus minimal gap is depicted in Fig. 5. 


\section{Sliding surfaces deformation calculation model}

Determination of bearing sliding surfaces deformations under the action of fluid film pressure requires, in general case, finding the solution to the three-dimensional elasticity problem, which is done in the present paper with the help of the finite elements method. Three-dimensional 20-node solid finite elements are used for three-dimensional bearing model development [7]. Equations describing three-dimensional body deformations are reduced to the system of linear equations, as follows:

$$
\left[K_{d}\right]\{U\}=\left\{Q_{d}\right\},
$$

where $\left[K_{d}\right]$ and $\left\{Q_{d}\right\}$ are the system matrix and right side vector of the system of finite-element equations. Typical finite-element mesh for the multilobe axial bearing is represented in Fig. 8. Solution to the problem is found in an iterative way. At the first step, the bearing is assumed rigid $\left(h_{d e f}(r, \varphi)=0\right)$. In this case, pressure distribution in the fluid film is obtained from (7). Applying this pressure to the corresponding surfaces of the three-dimensional bearing model, we obtain the first deformation approximations and the first approximation for $h_{\text {def }}(r, \varphi)$ from (8). Correcting the fluid film thickness in (5) we get the new pressure distribution for the second step from (7) and then the second deformation approximations are obtained from (8) and so on. The iterative process is stopped when the changes in bearing carrying force and bearing elements deformations for two cumulative iterations are within the boundaries of the required tolerance.

\section{Thrust bearing fluid flow and stiffness parameters calculation}

\subsection{Calculations for the case of runner angular displacements taken into account}

The calculations of bearing characteristics are carried out by using the verified thrust bearing model for the 6-lobe bearing with the parameters mentioned above for different runner rotations with the shaft axis and sliding surfaces closures. The dependence of total carrying force and the moment for all bearing lobes versus minimal gap are plotted in Fig. 6 with the assumption of $\xi$ equal to zero (see Fig. 1). The increase in bearing runner angular displacement causes that the same values of the carrying force are obtained for a greater $h_{\min }$ value.

Three-dimensional graphs of bearing carrying force and moment versus shaft axis rotation angle $\gamma$ and the location of the runner rotation plane, determined by $\xi$, are shown in Fig. 7. The minimal initial gap is assumed $100 \mu \mathrm{m}$ in these calculations. 
ELASTOHYDRODYNAMIC CONTACT MODEL FOR CALCULATION OF AXIAL AND ANGULAR... 461

Thrust bearing characteristics with axial displacements and runner rotations are determined by the obtained dependencies. The carrying force characterizes axial stiffness and moments - angular stiffness at the point of the runner fastening to the shaft. Angular stiffness of the bearing, similarly as the axial one, also has a characteristic nonlinear dependency, which may be the reason for its considerable contribution to rotor nonlinear bending vibrations.

It is necessary to mention that, when the bearing runner angular displacements are taken into account, it is hard to obtain the dependencies of carrying force and moment due to their dependency on minimal gap $\left(h_{\min }\right)$, runner angular displacement $(\gamma)$ and the location of the runner rotation plane $(\xi)$. Therefore, for the finite element design of the thrust bearing support it is preferable to integrate the bearing's mathematical model into the rotor dynamics calculation scheme for the purpose of direct calculation of bearing characteristics for each case of dynamic problem calculation.

\subsection{Calculations for the case of sliding surfaces deformations taken into account}

The deformations of bearing sliding surfaces should be taken into account in calculations of the characteristics for large carrying force values and for the bearings with low elasticity modulus of the antifriction coating. The gap $h$ for the bearing with compliant surface is not constant, and can be determined from (5). On the basis of the algorithm for calculation of the thrust bearing characteristics with the sliding surfaces deformations taken into account, presented in this paper, we carried out the evaluation of contribution of the bearing surfaces deformability to the carrying force. The Calculations performed for the 6-lobe bearing with the parameters mentioned above (Fig. 1) with water and oil considered as lubricants. The deformable coating consists of an external PTFE (polytetrafluoroethylene) layer with elasticity modulus of $8 \cdot 10^{3} \mathrm{MPa}$, the Poisson ratio equal to 0.375 , and an intermediate bronze layer with modulus of elasticity of $1.127 \cdot 10^{5} \mathrm{MPa}$ and the Poisson ratio of 0.32. The PTFE and the bronze layer thicknesses are $0.025 \mathrm{~mm}$ and 0.275 $\mathrm{mm}$, respectively.

The calculations of bearing deformation under the action of the fluid film pressure are carried out with the help of the bearing solid model in a conventional finite-element software. The bearing geometry with the fasteners fixing it to the casing is shown in Fig. 1, the bearing finite-element model and the calculation results for deformations under a $50 \mathrm{kN}$ initial axial load acting on it are shown in Fig. 8. 


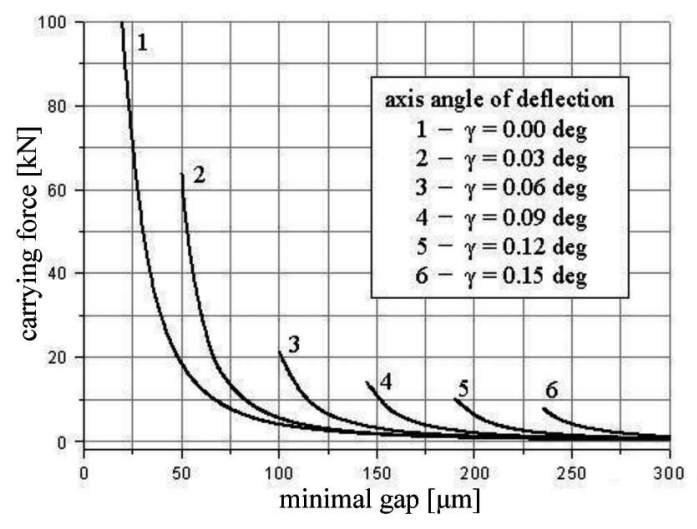

a)

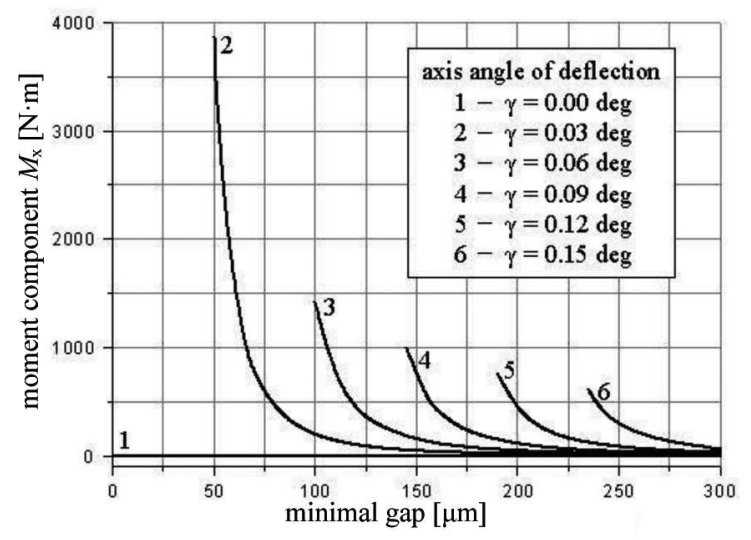

b)

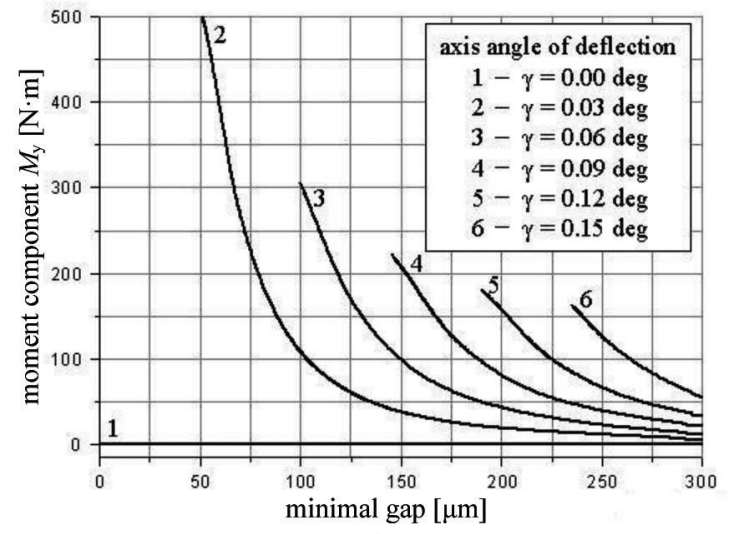

c)

Fig. 6. Thrust bearing stiffness characteristics for selected angles of deflection 


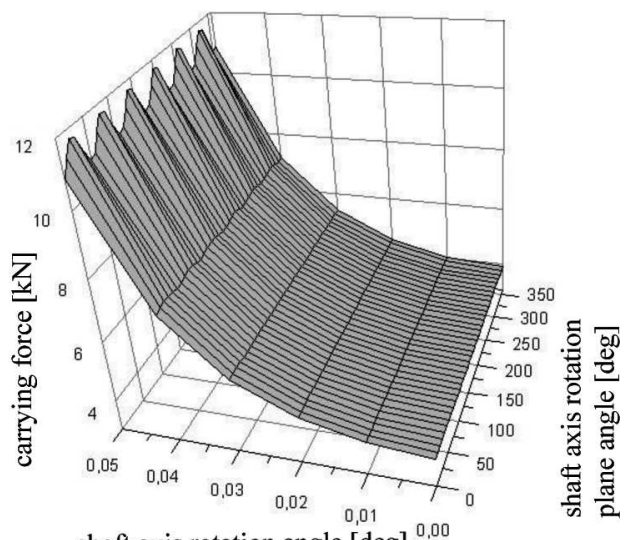

shaft axis rotation angle $[\mathrm{deg}]^{0,00}$

a)

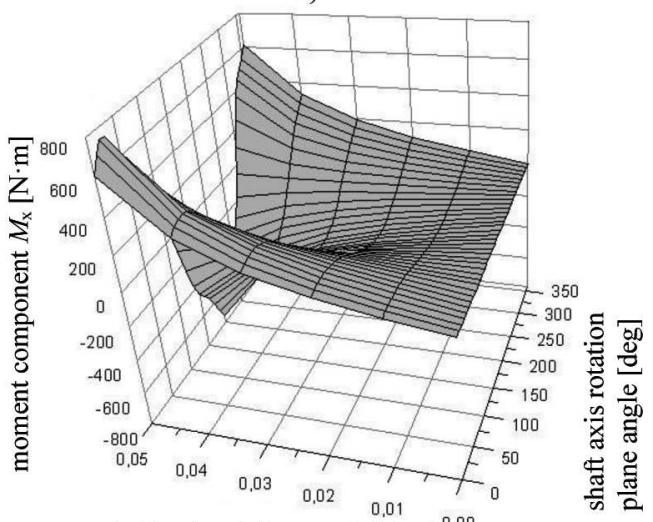

shaft axis rotation angle $[\mathrm{deg}]^{0,00}$

b)

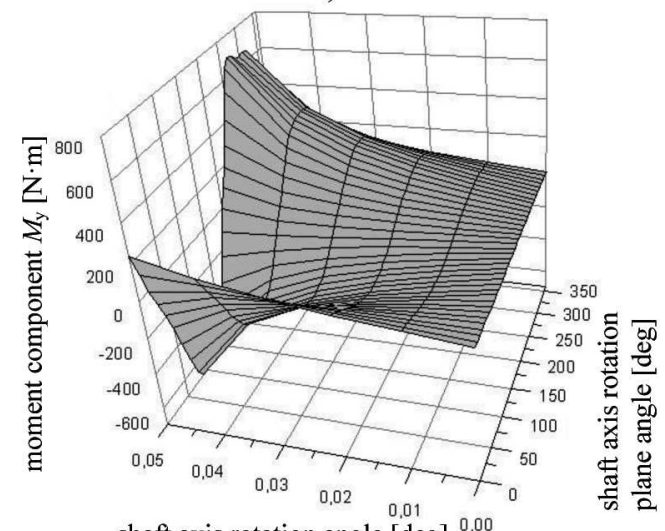

shaft axis rotation angle $[\mathrm{deg}]^{0,00}$

c)

Fig. 7. Thrust bearing stiffness characteristics 


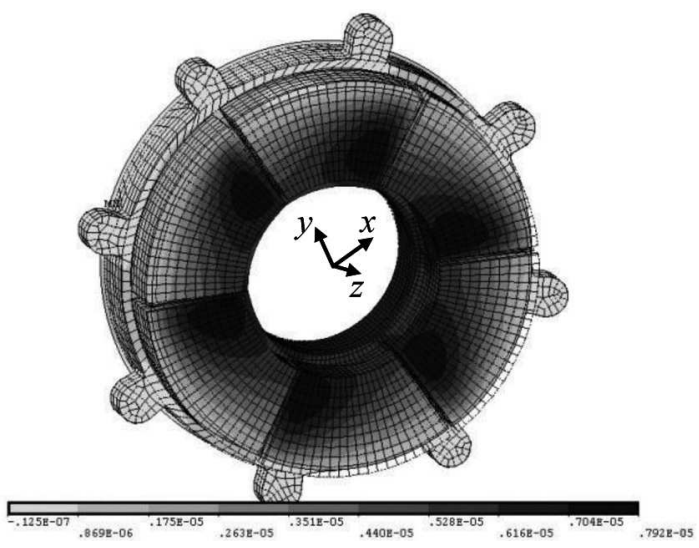

Fig. 8. Finite-element model and total displacements in $\mathrm{m}$ under the action of $39,2 \mathrm{kN}$ axial loading

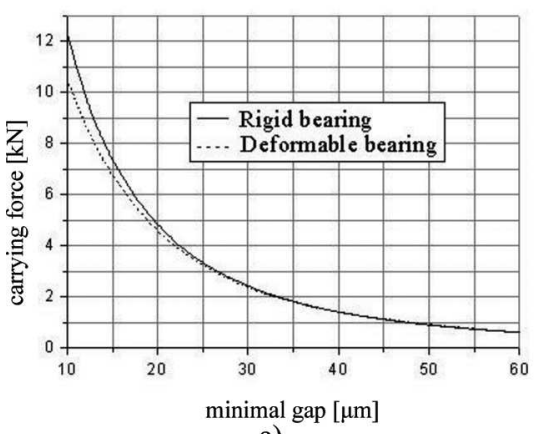

a)

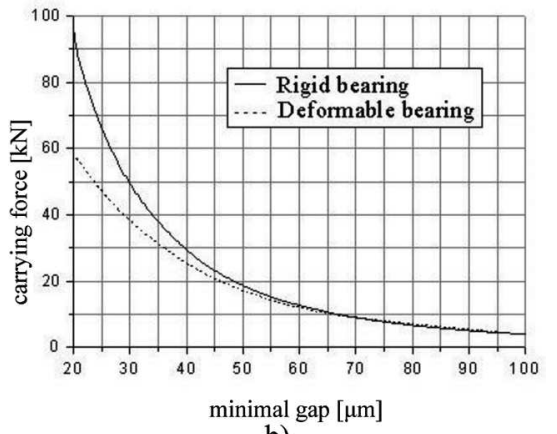

b)

Fig. 9. Thrust bearing carrying force for water lubrication (a) and oil lubrication (b)

The graph of bearing carrying force versus minimal gap before deformation for rigid and deformable sliding surfaces is shown in Fig. 9. The calculations were carried out for two lubricant types: water and oil with dynamic viscosity of $0.001 \mathrm{MPa} \cdot \mathrm{s}$ and $0.02 \mathrm{MPa} \cdot \mathrm{s}$, respectively. The deformed gap and the plots of pressure distribution in the sections that contain the point of maximum pressure on the bearing surface, under initial axial loading of $50 \mathrm{kN}$, for oil lubrication, are shown in Fig. 10. Fig. 10a correspond to the section with constant radius and Fig. $10 \mathrm{~b}$ - to the sections with constant angular coordinate. As it can be seen from calculation results, in the case of the small gap that corresponds to high axial loads, the bearing surface deformations have a considerable influence on its stiffness characteristics, particularly on the carrying force. 


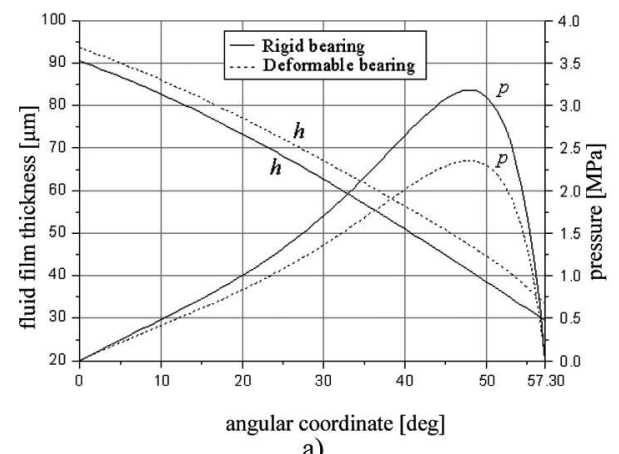

a)

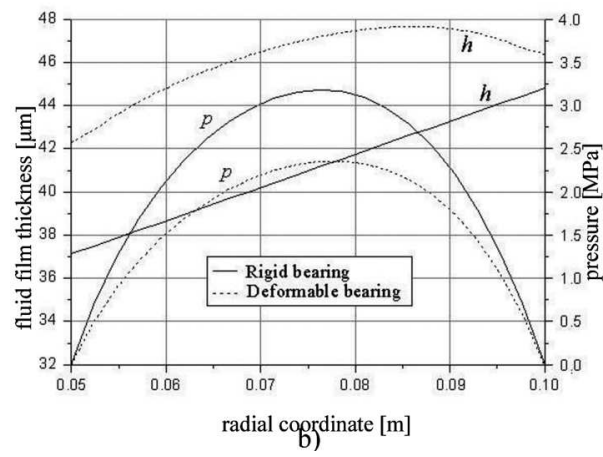

Fig. 10. Thrust bearing lobe characteristics under the action of $50 \mathrm{kN}$ initial axial loading for the sections passed through point $p=p_{\max }$

\section{Conclusion}

A mathematical model of a thrust bearing has been developed. This model, in the presence of axial and angular displacements of the runner, lets one to determine bearing stiffness characteristics with the sliding surfaces deformability and shaft bending taken into account. Verification of the fluid flow model is carried out on the basis of Reynolds equation by comparing its results with experimental and theoretical results from [1]. Numerical simulation results obtained via STAR-CD software have confirmed that accuracy of the developed model is sufficient. The dependencies of the bearing carrying force and moment components for a sample bearing structure, are calculated versus minimal gap $\left(h_{\min }\right)$, runner angular displacement $(\gamma)$ and the location of the runner rotation line $(\xi)$. They have shown that deformability of the sliding surfaces has a sufficient influence on bearing stiffness characteristics. The developed model is the basis for finite element formulation of the thrust bearing support applicable for the rotor dynamics investigation problem.

The developed methodology lets one to include the model of the thrust deformable bearing, considering runner angular displacements, into the axial support finite element model. That model, being a part of the total rotor finite-element model, takes the influence of the thrust bearing nonlinear characteristics on rotor dynamic behavior into account.

\section{Nomenclature}

$\left[K_{d}\right], \quad\left\{Q_{d}\right\} \quad-\quad$ the system matrix and right side vector for sliding surfaces deformation calculation;

$\left[K_{f}\left(h_{\text {def }}\right)\right], \quad\left\{Q_{f}\left(h_{\text {def }}\right)\right\}-$ the system matrix and the right side vector for pressure calculation; 
$\{p\}$

$\{U\}$

$f$

$f_{r}, f_{\varphi}, f_{z}$

$h=h(r, \varphi)$

$h^{*}$

$h_{\text {def }}=h_{d e f}(r, \varphi)$

$h_{\text {geom }}=h_{\text {geom }}(r, \varphi)$

$h_{\min }, h_{\max }$

l

$M_{x}, M_{y}$

n

N

$p=p(r, \varphi)$

$p_{\max }$

$r, \varphi, z$

$R_{1}, R_{2}$

$t$

$v_{r}, v_{\varphi}, v_{z}$

$x, y, z$

$\gamma$

$\eta$

$\theta$

$\xi$

$\rho$

$\omega$
- evaluated vector of pressure;

- evaluated vector of bearing deformations;

- function;

- mass forces vector components in cylindrical coordinates;

- function of fluid film thickness, $\mu \mathrm{m}$;

- characteristic dimension of bearing gap;

- fluid film thickness, determined by sliding surfaces deformations, $\mu \mathrm{m}$;

- fluid film thickness, determined by the initial form and the changes in sliding surfaces mutual position, $\mu \mathrm{m}$;

- minimal and maximal gap thicknesses for still shaft axis, $\mu \mathrm{m}$;

- sliding surfaces length for bearing;

- bearing moment components for runner angular displacements;

- lobe number;

- total number of lobes;

- pressure function over the lobe surface, MPa;

- maximal fluid pressure at the lobe, MPa;

- cylindrical coordinates, m;

- internal and external radii of bearing lobe, $\mathrm{mm}$;

- time, s;

- fluid flow velocity vector components in cylindrical coordinates, $\mathrm{m} / \mathrm{s}$;

- orthogonal coordinates, m;

- shaft axis rotation angle, deg;

- fluid dynamic viscosity, MPa·s;

- lobe angle, deg;

- angle of the shaft axis rotation plane, deg;

- fluid density, $\mathrm{kg} / \mathrm{m}^{3}$;

- shaft revolution speed, $\mathrm{rad} / \mathrm{s}$. 
Manuscript received by Editorial Board, October 10, 2011;

final version, November 13, 2012.

\section{REFERENCES}

[1] Mote C.D.,Jr., Schajer G.S., Telle L.I.: Hydrodynamic Sector Bearings as Circular Saw Guides, Journal of Lubrication Technology, January 1983, vol. 105, pp. 67-76.

[2] Temis J.M., Temis M.J.: Influence of Elastohydrodynamic Contact Deformations in Fluid Film Bearing on High-Speed Rotor Dynamic, Proc. 2nd Int. Symp. on Stability Control of Rotating Machinery, Gdansk, Poland, 2003, pp. 150-159.

[3] Temis J.M., Temis M.J.: Contribution of Bearing Structure in Gas Turbine Power Unit Rotor Dynamics, Proc. 3rd Int. Symp. on Stability Control of Rotating Machinery, Cleveland, USA, 2005, pp. 570-581.

[4] Temis J.M., Temis M.J.: Stiffness and Damping Characteristics of Fluid Film Bearing with Compliant Surfaces, Friction and Wear J., Gomel, Volume 28, No 2, 2007, pp. 128-137. (in Russian).

[5] Petrov N.P., Reynolds O., Sommerfeld A., Mitchel A., Zhukovsky N.E., Chaplyng S.A.: Hydrodynamic Theory of Lubrication, under edition with comments of LEIBENZON L.S., GTTI, M.-L., 1934, p. 575. (in Russian).

[6] Konstantinesku V.N.: Gas Lubrication, Mashinostroenie, M., 1968, p. 709, (in Russian).

[7] Bathe K-J.: Finite Element Procedures, Prentice Hall, 1995, p. 1037.

\section{Elastohydrodynamiczny model kontaktowy do obliczeń sztywności osiowej i kątowej łożysk oporowych}

\section{Streszczenie}

Opracowano model łożyska oporowego przeznaczony do obliczeń przepływu płynu i wyznaczania całościowych charakterystyk dla warunków gdy występuje zamknięcie szczeliny między ślizgającymi się powierzchniami i kątowe przemieszczenie wału. Model jest oparty na połączonych rozwiązaniach zagadnienia przepływu nieściśliwego płynu między ślizgającymi się powierzchniami i zagadnienia deformacji elementów łożyska i wału pod wpływem ciśnienia w warstwie płynu. Weryfikacja wyników modelu łożyska jest przeprowadzona przez ich porównanie z wynikami obliczeń przepływu płynu uzyskanymi przy użyciu oprogramowania STAR-CD oraz wynikami eksperymentalnymi i teoretycznymi podawanymi w literaturze. Charakterystyki łożyska ślizgowego są wyznaczone $\mathrm{z}$ uwzględnieniem zamknięcia szczeliny smarnej i przemieszczeń kątowych tarczy obrotowej (oporowej). Oszacowano wpływ, jaki mają odkształcenia ślizgających się powierzchni na całościowe charakterystyki łożyska. 